\title{
How Many Sexual Partners Are Too Many for Elderly Men From Rural China Who Visit Female Sex Workers Becoming HIV-Positive?
}

Yi Yang ( $\nabla$ thehanyang@163.com )

Chengdu University of Traditional Chinese Medicine

\section{ShuangFeng Fan}

Chengdu Center for Disease Control and Prevention

\section{Shu Liang}

Sichuan Center for Disease Control and Prevention

\section{Yang Liu}

Chengdu Center for Disease Control and Prevention

\section{Yuan Li}

Chengdu University of Traditional Chinese Medicine Jing Xi

Chengdu Center for Disease Control and Prevention

\section{Dan Yuan}

Sichuan Center for Disease Control and Prevention

Jie Xiao

Chengdu University of Traditional Chinese Medicine

\section{Research Article}

Keywords: Sexuality, Receiver-operating characteristics(ROC), Elderly men, Case-control study, HIV

Posted Date: December 2nd, 2021

DOI: https://doi.org/10.21203/rs.3.rs-1097555/v1

License: (1) (1) This work is licensed under a Creative Commons Attribution 4.0 International License. Read Full License 


\section{Abstract}

Objectives. To make clear how many sexual partners (SPs) are too many for elderly ( $\geq 50$ years old) men becoming HIV-positive from rural China.

Methods. We conducted a case-control study: 99 newly HIV (+) vs. 88 HIV (-) elderly men with similar age who visited female sex workers (FSW). Receiver-operating characteristics (ROC) curves and backward binary logistic regression was applied.

Results. Cases had more SPs (315.66 \pm 401.33$)$ than controls(14.63 \pm 25.63$)$ in their lifetime, mainly commercial SPs(313.98 \pm 401.38 vs.12.81 \pm 25.85$)$, similarly in the last three years. AUCs for HIV infection at number of accumulated SPs and of commercial SPs were 0.89 and 0.90 , and correspondingly 0.79 and 0.81 in the last three years. Cut-off values were identified as 51.5, 52.5, 5.5 and 4.5 based on Youden's indexes $(0.715,0.705,0.612$ and 0.601$)$. Risky factors for HIV infection among elderly men were having 52-2002 SPs in their lifetime (AOR (95\% Cl): 56.33(11.36-279.25)), having 5-289 commercial SPs in the last three years (11.55(2.78-47.94)).

Conclusions. $\geq 52$ SPs in their lifetime and $\geq 5 \mathrm{FSW}$ in the last three years are too many for elderly men from rural China becoming HIV-positive.

\section{Introduction}

China is facing big challenges to ending the AIDS epidemic as a public health threat ${ }^{[1,2]}$. One of the biggest challenges is that HIV prevalence of elderly ( $\geq 50$ years old) men has been steadily increasing ${ }^{[3-5]}$, much higher than the general population ${ }^{[6]}$. Due to immune functional decline and increased vulnerability to infections ${ }^{[7]}$, multiple morbidity ${ }^{[8]}$, HIV-positive elderly men quickly progress into AIDS even deaths ${ }^{[3,7]}$. Compared with other age groups, elderly men have minimal knowledge about AIDS ${ }^{[9]}$, condom use among them is even lower ${ }^{[10,11]}$. On one hand, HIV-positive elderly men could be a newly infected group. On the other hand, current elderly men are from previous sexually active 20-50-year-old group who might be HIV-positive but were not detected.

Sexual behaviors of elderly men in China are far from well-studied. Elderly men in China, who are considered as sexually inactive ${ }^{[12]}$ and had been excluded from the priority of HIV prevention programs $^{[13-16]}$, are not recognized and listed as a key prevention group until 2017 for the first time ${ }^{[17]}$. Due to convention ${ }^{[18]}$ and stigma ${ }^{[19]}$, Chinese, especially elderly people, do not talk about sex. Previous studies of sexual behaviors in China mainly focus on 20-50-year-old group ${ }^{[10,20-27]}$. Based on data from national HIV Sentinel Surveillance System(NHSSS) ${ }^{[3-5]}$, heterosexual transmission has been widely accepted as the major route for HIV epidemics in China. Another key concern is men who have sex with men (MSM). It is estimated that MSM account for $1.73 \%$ of $18-64$-year-old men in China ${ }^{[28]}$, and HIV infection among them continue to expand just as in most countries ${ }^{[29]}$. 
The contributions of heterosexual behavior and homosexual behavior in HIV infection among elderly men in China is not clear at population level. It is not clear which kind of heterosexual behavior play the most important role. Whether it is commercial heterosexual behavior, non-commercial extramarital sexual behavior, or casual sexual behavior? More importantly, how many sexual partners is too many for elderly men becoming HIV-positive? Are there certain methods to find out the cut-off points for "high-risk" groups?

Receiver-operating characteristics (ROC) curves have been applied to evaluate the accuracy (sensitivity and specificity) of parameters in predicting risks obtaining such as HIV infection, and identify the most suitable cut-off points for prediction[30, 31].

\section{Methods}

This study was a case-control study with 99 cases and 88 controls who visited female sex workers (FSW) in their lifetime, and the protocol was approved.

\section{Study Site}

Chengdu, the capital city of Sichuan province, is a one of the unique suitable study sites in China. One of fifth people living with HIV(PLHIV) in Sichuan are from Chengdu. Located in southwest of China, Sichuan province is one of the few provinces in China heavily affected by the HIV epidemic, though successful comprehensive HIV prevention strategies has been applied ${ }^{[1]}$. There are two major characteristics of HIV epidemics in Sichuan: HIV prevalence consistently increasing among elderly population and high prevalence of HIV infection among MSM in Chengdu. Elderly people in Sichuan accounted for less than $5 \%$ of PLHIV in 2005, and over $40 \%$ in 2017 , and $59.2 \%$ in $2019^{[1,5]}$, meanwhile the proportion of elderly men in the population is less than $40 \%{ }^{[32]}$. The overall HIV prevalence among MSM in Chengdu between 2009 and 2014 was 15.5\% ${ }^{[33]}$. Between 2012 and 2018, the HIV incidence density among MSM decreased annually, but the total incidence density was as high as 5.95 (95\% Cl: 5.37-6.56)/100 person-years ${ }^{[34]}$. Moreover, in $2013,17.9 \%$ of MSM reported that they had sex with both men and women(MSM/W), and living in Chengdu was found out as risk factor ${ }^{[35]}$.

With the coverage of sentinel surveillance improving ${ }^{[1]}$ and around 800,000 population ${ }^{[36]}$, rural County $\mathrm{A}$ in Chengdu ranked one of the top five counties in the number of PLHIV, mainly from male group.

\section{Case Group}

The selection criteria included: (1) $\geq 50$ years old; (2) male; (3) live in the current address for at least six months;(4) newly diagnosed HIV (+); (5) self-report visiting FSW in their lifetime; (6) willing to participate the study.

During April 2019 and October2020, 115 elderly men from 8 townships in County A were confirmed as HIV (+), and 114 participated the study. In their lifetime, 106 of 114(92.98\%) in case group reported 
visiting FSW. We obtained 99 cases' numbers of different types of accumulated sexual partners and sexual partners in the last three years in detail.

\section{Control Group}

The selection criteria included: (1) $\geq 50$ years old; (2) male; (3) live in the current address for at least six months;(4) HIV (-); (5) self-report visiting FSW in their lifetime; (6) willing to participate the study.

During June to July 2019 , a cross-sectional study from the same townships of case was conducted, 802 men were recruited, and 797(99.38\%) questionnaires were reliable, and among them 795 were HIV (-) $)^{[37]}$. 88 of 795(11.07\%) HIV (-) respondents admitted visiting FSW in their lifetime.

\section{Data Collection}

A written informed consent was completed before the investigation. Local slangs were used to refer sexual behaviors. An in-depth interview with one case was conducted by one skilled medical staff from County A center for disease prevention and control (CDC). In total, two medical staff conducted the surveys in separate rooms in $\mathrm{CDC}$, county infectious hospital, or township health centers according to cases' convenience. A 30-minute face-to-face structured interview with a control was conducted in a separate room at the village health centers to make sure the respondents felt comfortable to talk about their sexual behaviors by one well-trained male interviewer.

\section{Measures}

Basic information demographic characteristics, migration experiences.

Biology sexual desire changes after the age of 50(no sexual need/decline/no change/increase).

Psychology sexual identity (heterosexual/homosexual/bisexual).

\section{Sexual behavior}

Numbers of different types of accumulated sexual partners and sexual partners in the last three years were measured, including fixed sexual partners, extramarital sexual partners, casual sexual partners and commercial sexual partners. In order to make respondents feel comfortable about the survey, homosexual behavior was measured only whether they had homosexual behaviors or not without asking the specific number.

\section{Health Services}

Whether they had heard of AIDS before the investigation for HIV (-) ones was asked. Then, HIV-related health education (HRHE) was measured in detail, including whether they got HRHE before, what kind of health educator provided HRHE before their HIV confirmation for cases and before the investigation for controls, including health workers from $\mathrm{CDC}$, health workers from township health center/village doctors, 
doctors from other hospitals, their children/grandchildren's teachers(primary school and high schools), township civil servants, village cadres, pharmacy staff, HIV-related service volunteers, and others.

\section{ROC}

Receiver-operating characteristics (ROC) curves were plotted to establish cut-off values of numbers of different sexual partners associated with HIV infection. The validity of the model was measured by the area under the curve (AUC). The more AUC reach 1, the more the data is well modelled. Based on Youden's indexes (Sensitivity +Specificity-1), the most suitable cut-off values were identified. The more Youden's index is close to 1 , the more accurately the cut-off points can distinguish the difference.

\section{Data analysis}

Frequencies for nominal variables, mean and standard deviation for interval variables were assessed. $T$ test and Chi-square tests/ fisher's exact test were used to examine the relationships between HIV infection and independent variables. Binary logistic regression with backward selection was applied to examine factors associated with HIV infection, including all factors with $p<0.05$ in bivariate analyses. Adjusted odds ratio (AOR) and 95\% confidence intervals were calculated. Factors with AOR greater than one was categorized as risk factors, and less than one as protective factors.

\section{Results}

\section{Basic Information}

The age was $63.28 \pm 8.62$ for cases, $61.63 \pm 7.08$ for controls, the difference was not statistically significant $(t=1.43, P=0.16)$, similar with the differences of types of residency, education levels, marital statuses, monthly expenses for entertainment and migration experiences between two groups $(P>0.05)$. In terms of latest occupations, types of living with, monthly income, the differences between two groups were statistically significant $(P<0.05)$, details are showed in Table1.

Table 1 Basic Characteristics Comparison Between HIV (+) vs. HIV (-) Elderly Men in Chengdu, China $(n=187, n(\%))$ 


\begin{tabular}{|c|c|c|c|c|}
\hline & $\begin{array}{l}\text { HIV (+) } \\
(n=99)\end{array}$ & $\begin{array}{l}\text { HIV }(-) \\
(n=88)\end{array}$ & $\chi^{2}$ & $P$ \\
\hline type of residency & & & 3.23 & 0.07 \\
\hline city & $10(10.1)$ & $3(3.41)$ & & \\
\hline rural & $89(89.9)$ & $85(96.59)$ & & \\
\hline Education level & & & 1.97 & 0.85 \\
\hline illiterate & $16(16.16)$ & $16(18.18)$ & & \\
\hline Primary school drop outs & $35(35.35)$ & $25(28.41)$ & & \\
\hline Primary school & $14(14.14)$ & $14(15.91)$ & & \\
\hline Junior high school drop outs & 13(13.13) & $9(10.23)$ & & \\
\hline Junior high school & 19(19.19) & $22(25)$ & & \\
\hline Senior high school/technical school & $2(2.02)$ & $2(2.27)$ & & \\
\hline Marital status & & & 1.34 & 0.51 \\
\hline never married & $68(68.69)$ & $63(71.59)$ & & \\
\hline married & $4(4.04)$ & $6(6.82)$ & & \\
\hline single(divorce/widow/separated) & $27(27.27)$ & 19(21.59) & & \\
\hline Latest occupation & & & & $<0.01^{*}$ \\
\hline Farm workers/workers & $89(89.9)$ & $62(70.45)$ & & \\
\hline Government employees & $8(8.08)$ & $20(22.73)$ & & \\
\hline Other & $2(2.02)$ & $6(6.82)$ & & \\
\hline Living with & & & & $<0.047^{\star}$ \\
\hline Only spouse & $25(25.25)$ & $33(37.5)$ & & \\
\hline $\begin{array}{l}\text { Spouses and other family members (parents or } \\
\text { children) }\end{array}$ & $32(32.32)$ & $33(37.5)$ & & \\
\hline Only other family members (parents or children) & 23(23.23) & $8(9.09)$ & & \\
\hline Nobody & 16(16.16) & $13(14.77)$ & & \\
\hline In facilities & $1(1.01)$ & $1(1.14)$ & & \\
\hline other & $2(2.02)$ & $0(0)$ & & \\
\hline
\end{tabular}




\begin{tabular}{|c|c|c|c|c|}
\hline & $\begin{array}{l}\text { HIV (+) } \\
(n=99)\end{array}$ & $\begin{array}{l}\text { HIV }(-) \\
(n=88)\end{array}$ & $x^{2}$ & $P$ \\
\hline Monthly income & & & 14.97 & $<0.01$ \\
\hline$<1000$ YUAN & $26(26.26)$ & $43(48.86)$ & & \\
\hline 1000-1999YUAN & $21(21.21)$ & $21(23.86)$ & & \\
\hline 2000-2999YUAN & 19(19.19) & $12(13.64)$ & & \\
\hline $3000 Y U A N$ and above & 33(33.33) & 12(13.64) & & \\
\hline Monthly expense for entertainment & & & & $0.49^{*}$ \\
\hline$<500$ YUAN & $56(56.57)$ & $54(61.36)$ & & \\
\hline 500-999YUAN & $26(26.26)$ & $27(30.68)$ & & \\
\hline 1000-1499YUAN & $10(10.1)$ & $4(4.55)$ & & \\
\hline 1500-1999YUAN & $3(3.03)$ & $1(1.14)$ & & \\
\hline 2000YUAN and above & $4(4.04)$ & $2(2.27)$ & & \\
\hline Migration history & & & 0.52 & 0.77 \\
\hline More than one year ago & $54(54.55)$ & $48(54.55)$ & & \\
\hline Within the past one year & $26(26.26)$ & $20(22.73)$ & & \\
\hline Never & 19(19.19) & $20(22.73)$ & & \\
\hline
\end{tabular}

\section{HIV-related Health Education}

22 of 99(22.22\%) cases had gotten HRHE before, lower than controls $(50 / 88,56.82 \%)(P<0.05)$. Neither of cases and controls had gotten HRHE from pharmacies, HIV-related service volunteers and their children/grandchildren's teachers (primary school and high schools). Controls had gotten HRHE more from health workers from township health center/village doctors $(60.00 \%)$, health workers from CDC $(36.00 \%)$, and less from others $(8.00 \%)$ than cases $(4.50 \%, 0.0 \%$ and $86.36 \%)(P<0.05)$, details are showed in Table2.

Table 2 HIV-related Health Educator Comparison Between HIV (+) vs. HIV (-) Elderly Men in Chengdu, China $(n=72, n(\%))$ 


\begin{tabular}{|lllll|}
\hline & $\begin{array}{l}\text { HIV }(+) \\
(\mathbf{n = 2 2})\end{array}$ & $\begin{array}{l}\text { HIV }(-) \\
(\mathbf{n = 5 0}\end{array}$ & $\chi^{2}$ & $P$ \\
\hline health workers from CDC & $0(0)$ & $18(36.00)$ & 10.56 & $<0.01$ \\
\hline $\begin{array}{l}\text { health workers from township health center/village } \\
\text { doctors }\end{array}$ & $1(4.50)$ & $30(60.00)$ & 19.16 & $<0.01$ \\
\hline doctors from other hospitals & $0(0)$ & $2(4.00)$ & & $1.00^{*}$ \\
\hline township civil servants & $0(0)$ & $8(16.00)$ & $0.10^{*}$ \\
\hline village cadres & $1(4.55)$ & $7(14.00)$ & $0.42^{*}$ \\
\hline others & $19(86.36)$ & $4(8.00)$ & 43.16 & $<0.01$ \\
\hline *: fisher's exact test & & & & \\
\hline
\end{tabular}

\section{Sexual Desire Changes, Sexual Identity and Homosexual Behavior}

Sexual desire after the age of 50 for $74.75 \%$ (74/99) cases and $77.27 \%(68 / 88)$ controls declined, the difference was not statistically significant $(P>0.05)$.

99 of $99(100 \%)$ cases and 86 of $88(97.73 \%)$ controls reported themselves as heterosexual, and 2 of 88 $(2.27 \%)$ controls reported as bisexual, the difference was not statistically significant $(P>0.05)$.

2 of $99(2.02 \%)$ cases and 2 of $88(2.27 \%)$ controls were involved in homosexual behaviors $(P>0.05)$.

\section{Number of Sexual Partners}

Cases had more sexual partners in their lifetime, mainly commercial sexual partners than controls $(P<0.01)$, similarly in the last three years $(P<0.01)$. Details are showed in Table 3 .

Table 3 Sexual Behaviors Comparison Between HIV (+) and HIV (-) Elderly Men in Chengdu, China ( $n=187$, $\overline{\mathrm{x}} \pm \mathrm{s})$ 


\begin{tabular}{|lllll|}
\hline & $\begin{array}{l}\text { HIV }(+) \\
(\mathbf{n = 9 9 )}\end{array}$ & $\begin{array}{l}\text { HIV }(-) \\
(\mathbf{n}=\mathbf{8 8})\end{array}$ & $\mathbf{t}$ & $\mathbf{P}$ \\
\hline Accumulated No. of sexual partners & $315.66 \pm 401.33$ & $14.63 \pm 25.63$ & 7.45 & $<0.01$ \\
\hline fixed sexual partners & $1.19 \pm 0.67$ & $1.15 \pm 0.67$ & 0.45 & 0.65 \\
\hline extramarital sexual partners & $0.44 \pm 2.55$ & $0.44 \pm 0.92$ & 0.00 & 1.00 \\
\hline casual sexual partners & $0.04 \pm 0.24$ & $0.23 \pm 0.87$ & -1.95 & 0.05 \\
\hline commercial sexual partners & $313.98 \pm 401.38$ & $12.81 \pm 25.85$ & 7.45 & $<0.01$ \\
\hline No. of sexual partners in the last three years & $31.21 \pm 49.31$ & $1.9 \pm 4.34$ & 5.89 & $<0.01$ \\
\hline fixed sexual partners & $0.7 \pm 0.65$ & $0.8 \pm 0.41$ & -1.26 & 0.21 \\
\hline extramarital sexual partners & $0.08 \pm 0.27$ & $0.02 \pm 0.15$ & 1.83 & 0.07 \\
\hline casual sexual partners & $0.01 \pm 0.1$ & $0.03 \pm 0.32$ & -0.71 & 0.48 \\
\hline commercial sexual partners & $30.43 \pm 49.36$ & $1.05 \pm 4.42$ & 5.90 & $<0.01$ \\
\hline
\end{tabular}

AUCs for HIV infection at accumulated number of sexual partners and of commercial sexual partners were $0.89(95 \% \mathrm{Cl}, 0.84-0.94, \mathrm{P}<0.01)$ and $0.90(95 \% \mathrm{Cl}, 0.85-0.94, \mathrm{P}<0.01)$. The counterpart AUCs in the last three years were $0.79(95 \% \mathrm{Cl}, 0.72-0.86, \mathrm{P}<0.01)$ and $0.81(95 \% \mathrm{Cl}, 0.74-0.87, \mathrm{P}<0.01)$. Details are showed in Table 4 and figure1.

Table 4 Area Under the Curve for HIV infection among Elderly Men in Chengdu, China $(n=187)$ 


\begin{tabular}{|lllll|}
\hline Test Result Variable(s) & Area & \multicolumn{2}{l}{$95 \%$ Confidence Interval } & $P$ \\
\cline { 3 - 4 } & & Lower Bound & Upper Bound & \\
\hline Accumulated No. of sexual partners & 0.89 & 0.84 & 0.94 & $<0.01$ \\
\hline fixed sexual partners & 0.53 & 0.45 & 0.61 & 0.49 \\
\hline extramarital sexual partners & 0.45 & 0.36 & 0.53 & 0.20 \\
\hline casual sexual partners & 0.47 & 0.39 & 0.55 & 0.47 \\
\hline commercial sexual partners & 0.90 & 0.85 & 0.94 & $<0.01$ \\
\hline No. of sexual partners in the last three years & 0.79 & 0.72 & 0.86 & $<0.01$ \\
\hline fixed sexual partners & 0.44 & 0.35 & 0.52 & 0.13 \\
\hline extramarital sexual partners & 0.53 & 0.45 & 0.61 & 0.49 \\
\hline casual sexual partners & 0.50 & 0.42 & 0.58 & 0.99 \\
\hline commercial sexual partners & 0.81 & 0.74 & 0.87 & $<0.01$ \\
\hline
\end{tabular}

Based on Youden's indexes $(0.715,0.705,0.612$ and 0.601$)$, cut-off values of accumulated number of sexual partners and of commercial sexual partners, number of sexual partners and of commercial sexual partners in the last three years were identified as $51.5,52.5,5.5$ and 4.5 .

\section{Correlation between numbers of sexual partners and HIV Infection}

Risky factors for HIV infection among elderly men were having 52-2002 sexual partners in their lifetime (AOR (95\%Cl): 56.33(11.36-279.25)), having 5-289 commercial sexual partners in the last three years (11.55(2.78-47.94)), and having 3000YUAN and above(9.02(2.04-39.96)) and 2000-2999YUAN(4.21(1.0516.85)) monthly income, not receiving HRHE (3.57(1.1-11.64)). Details are showed in Table 5.

Table 5 Association between HIV infection and related factors among Elderly Men in Chengdu, China, bivariate and multivariate analyses, backward logistic regression $(n=187)$ 


\section{Monthly income (vs. <1000YUAN)}

\begin{tabular}{lll}
\hline 1000-1999YUAN & $1.65(0.76-3.6)$ & $1.07(0.26-4.36)$ \\
\hline 2000-2999YUAN & $2.62(1.1-6.26)$ & $4.21(1.05-16.85)$ \\
\hline 3000YUAN and above & $4.55(2-10.33)$ & $9.02(2.04-39.96)$ \\
\hline HIV-related Health Education (no vs. yes) & $4.61(2.44-8.68)$ & $3.57(1.1-11.64)$ \\
\hline Accumulated No. of sexual partners (52-2002 vs. 1-51) & $120.73(27.71-$ & $56.33(11.36-$ \\
\hline $\begin{array}{l}\text { No. of commercial sexual partners in the last three years (5- } \\
\mathbf{2 8 9} \text { vs. 0-4) }\end{array}$ & $\begin{array}{l}38.4(12.98- \\
113.57)\end{array}$ & $\begin{array}{l}11.55(2.78- \\
47.94)\end{array}$ \\
\hline
\end{tabular}

Note: Variable(s) entered on step 1: Accumulated No. of sexual partners Accumulated, No. of commercial sexual partners, No. of sexual partners in the last three years, No. of commercial sexual partners in the last three years, Latest occupation, living with, Monthly income, HIV-related Health Education

\section{Discussion}

As a case-control study, this study design is well organized, and proves that having more than 52 and above sexual partners in their lifetime and visiting 5 and above FSW in the last three years are too many for elderly men from rural China becoming HIV-positive. Becoming HIV-positive among elderly men is not related with sexual desire change and sexual identity. As groups visiting FSW in their lifetime, risks of HIV infection do not come from their unmarried statuses, neither from whom they live with, even not from migration experiences.

It is not suddenly that elderly men become HIV-positive, but rather delayed detections. In this study, around 80 percent of the respondents from both groups had migration experience. Back to 1980s, they were 20-50-year-old, sexually active, and migrated alone, easy to be involved in high-risk sexual behaviors such as visiting FSW and having sex with men to fulfil their emotional and sexual needs ${ }^{[10,18,20-24,27]}$.

Without doubt, HRHE helps elderly men avoid becoming HIV-positive. Rather than from informal channel(other), getting HRHE from formal channels (health workers from CDC, health workers from township health center/village doctors) helps elderly men avoid HIV infection. However, comparing with having multiple sexual partners and visiting FSW, the protective role of HRHE is small.

In this study, 2 of 99 cases $(2.02 \%)$ and 2 of 88 controls(2.27\%) were MSM, a little higher than national level(1.73\% ${ }^{[28]}$. 2 of 2 MSM cases self-reported as heterosexual, and 2 of 2 controls self-reported as bisexual. All of them were MSM/W. MSM in China are facing stigma and family pressure to get married and have children that make HIV(+) MSM transmit HIV infection from their homosexual partners ${ }^{[29,38]}$ to their wives ${ }^{[39]}$. 


\section{Limitations}

The current study should be noted self-report behavior information. Face-to-face interviews may heighten socially desirable responses such as low report of high-risk sexual behaviors. In order to confront the problems, our interviewers were well trained, interviews were conducted in separate rooms, and local slangs were used.

Moreover, in-depth interviews were conducted by skilled medical staffs from County A CDC for case group, but by well-trained young male interviewers for control group. Informational bias due to different types of interviewers was inevitable, and would overestimate the difference between two groups. In order to minimize the bias, interviewers were trained by same trainers, only well interviewers conducted the indepth interview, and interviewers followed the same in-depth procedure.

Though we conduct census among HIV (+) elderly male population, due to limited sample size, we can't confirm our suspicion about the role of homosexual behavior in HIV infection among elderly men. We will continue to conduct researches to confirm our suspicion.

\section{List Of Abbreviations}

SPs: sexual partners

NHSSS: HIV Sentinel Surveillance System

MSM: men who have sex with men

FSW: female sex workers

PLHIV: people living with HIV

MSM/W: men who have sex with both men and women

CDC: center for disease prevention and control

HRHE: HIV-related health education

ROC: Receiver-operating characteristics

AUC: area under the curve

AOR: Adjusted odds ratio

\section{Declarations}


The institutional review board (IRB) from affiliated hospital of Chengdu University of Traditional Chinese Medicine approved the protocol (reference number: 2019KL-008). All methods were performed in accordance with the relevant guidelines and regulations including a statement. A written informed consent was completed before the investigation, and respondents agreed to participate the study and agreed that their information can be published anonymously if needed.

\section{Consent for publication}

A written informed consent was completed before the interviews, and respondents agreed that their information can be published anonymously if needed.

\section{Availability of data and materials}

The datasets analyzed during the current study are available from the corresponding author on reasonable request.

\section{Competing Interests}

The authors declare that they have no competing interests.

\section{Funding}

This study was supported by National Natural Science Foundation of China (Grant \#81803300) and humanities and social science projects of the Ministry of Education of China (Grant \#18YJA840018).

\section{Authors' contributions}

YY and SF analyzed the data and was a major contributor in writing the manuscript. SL and YL helped to wrote and double checked the manuscript. YL and JX helped to analyze the data. DY and JX organized and conducted the investigation. All authors read and approved the final manuscript.

\section{Acknowledgments}

We would like to acknowledge the contributions of township health centers, Pengzhou District CDC, and Chengdu CDC, and RuiPing Liao, Xia Wu, Na Li, Wei Xiao, Guotao Luo, Yunrui Bai, Xuesong Wang, Fengsheng Leng, Yiji Wan, Run Zhong Wang in the data collection.

\section{References}

1. Zhang, L., et al., Comprehensive HIV/AIDS Programs in Sichuan. HIV/AIDS in China 2019: p. 629-651.

2. Degenhardt, L., et al., What has been achieved in HIV prevention, treatment and care for people who inject drugs, 2010-2012? A review of the six highest burden countries. International Journal of Drug Policy, 2014. 25(1): p. 53-60. 
3. Qiao, Y.-c., et al., Epidemiological analyses of regional and age differences of HIV/AIDS prevalence in China, 2004-2016. International Journal of Infectious Diseases, 2019. 81: p. 215-220.

4. Liu, H., et al., Emerging HIV Epidemic Among Older Adults in Nanning, China. AIDS Patient Care and STDs, 2012. 26(10): p. 565-567.

5. Fsya, B., et al., Epidemiological and spatiotemporal analyses of HIV/AIDS prevalence among older adults in Sichuan, China between 2008 and 2019: A population-based study - ScienceDirect. International Journal of Infectious Diseases, 2021.

6. Wang, Y.Y., et al., Older adults at high risk of HIV infection in China: a systematic review and metaanalysis of observational studies. Peerj, 2020. 8.

7. Leng, S.X. and J.B. Margolick, Aging, sex, inflammation, frailty, and CMV and HIV infections. Cellular Immunology, 2020. 348.

8. Smit, M., et al., Future challenges for clinical care of an ageing population infected with HIV: a modelling study. Lancet Infectious Diseases, 2015. 15(7): p. 810-818.

9. Zhang, T.Q., et al., Awareness of HIV/AIDS and its routes of transmission as well as access to health knowledge among rural residents in Western China: a cross-sectional study. Bmc Public Health, 2019. 19(1).

10. Yang, Y., et al., Condom Use During Commercial Sex Among Male Clients of Female Sex Workers in Sichuan China: A Social Cognitive Theory Analysis. Aids \& Behavior, 2016: p. 1-9.

11. Tuddenham, S.A., et al., Patients fifty years and older attending two sexually transmitted disease clinics in Baltimore, Maryland. International journal of STD \& AIDS, 2017. 28(4): p. 330-344.

12. Diokno, A.C., Morton B. Brown, and A. Regula Herzog., Sexual function in the elderly. Archives of Internal Medicine, 1990. 150(1): p. 197-200.

13. Zhang, L., et al., HIV prevalence in China: integration of surveillance data and a systematic review. The Lancet infectious diseases, 2013. 13(11): p. 955-963.

14. Kang, S.-C., S.-J. Hwang, and W.-W. Wong, Characteristics of human immunodeficiency virus infections among the elderly in Taiwan: a nationwide study. Journal of the Chinese Medical Association, 2011. 74(5): p. 215-219.

15. Jia, Z.W., et al., Tracking the Evolution of HIV/AIDS in China from 1989-2009 to Inform Future Prevention and Control Efforts. Plos One, 2011. 6(10).

16. Cui, Y., C.X. Shi, and Z. Wu, Epidemiology of HIV/AIDS in China: recent trends. Global Health Journal 2017. 1(1): p. 26-32.

17. Council, O.o.C.S., China's 13th Five-year Action plan for AIDS prevention and control. 2017.

18. Zhang, K., et al., Changing sexual attitudes and behaviour in China: implications for the spread of HIV and other sexually transmitted diseases. Aids Care-Psychological and Socio-Medical Aspects of Aids/Hiv, 1999. 11(5): p. 581-589.

19. Genberg, B.L., et al., A comparison of HIV/AIDS-related stigma in four countries: Negative attitudes and perceived acts of discrimination towards people living with HIV/AIDS. Social Science \& Medicine, 
2009. 68(12): p. 2279-2287.

20. Tucker, J.D., et al., Surplus men, sex work, and the spread of HIV in China. Aids, 2005. 19(6): p. 539547.

21. Reilly, K.H., et al., HIV and associated risk factors among male clients of female sex workers in a Chinese border region. Sexually Transmitted Diseases, 2012. 39(10): p. 750-755.

22. Zhang, C., et al., Prevalence of HIV, syphilis, and HCV infection and associated risk factors among male clients of low-paying female sex workers in a rural county of Guangxi, China: a cross-sectional study. Sexually Transmitted Infections, 2014. 90(3): p. 230-236.

23. Lau, J.T.F., et al., Prevalence of bisexual Behaviors among men who have sex with men (MSM) in China and associations between condom use in MSM and heterosexual behaviors. Sexually Transmitted Diseases, 2008. 35(4): p. 406-413.

24. Song, Y., et al., HIV-testing behavior among young migrant men who have sex with men (MSM) in Beijing, China. Aids Care-Psychological and Socio-Medical Aspects of Aids/Hiv, 2011. 23(2): p. 179186.

25. Liao, M., et al., Bisexual behavior and infection with HIV and syphilis among men who have sex with men along the east coast of China. AIDS Patient Care and STDs, 2011. 25(11): p. 683-691.

26. Huang, L., et al., Sociodemographic and sexual behavior characteristics of an online MSM sample in Guangdong, China. AIDS Care - Psychological and Socio-Medical Aspects of AIDS/HIV, 2014. 26(5): p. 648-652.

27. Wang, B., et al., HIV-related risk behaviors and history of sexually transmitted diseases among male migrants who patronize commercial sex in China. Sexually Transmitted Diseases, 2007. 34(1): p. 18.

28. Hu, M.G., C.D. Xu, and J.F. Wang, Spatiotemporal Analysis of Men Who Have Sex With Men in Mainland China: Social App Capture-Recapture Method. Jmir Mhealth and Uhealth, 2020. 8(1).

29. Beyrer, C., et al., Global epidemiology of HIV infection in men who have sex with men. Lancet, 2012. 380(9839): p. 367-377.

30. Lin, Z.-H., et al., Performance of the Aspartate Aminotransferase-to-Platelet Ratio Index for the Staging of Hepatitis C-Related Fibrosis: An Updated Meta-Analysis. Hepatology, 2011. 53(3): p. 726736.

31. Chou, R., et al., Preexposure Prophylaxis for the Prevention of HIV Infection Evidence Report and Systematic Review for the US Preventive Services Task Force. Jama-Journal of the American Medical Association, 2019. 321(22): p. 2214-2230.

32. Sichuan Statistics Bureau, C., 2018 Sichuan Provincial Demographic Bulletin. 2019.

33. Duan, Z.H., et al., Consistently high HIV prevalence among men who have sex with men in Chengdu city from 2009 to 2014. International Journal of Std \& Aids, 2016. 27(12): p. 1057-1062.

34. You, X.Y., et al., HIV incidence and sexual behavioral correlates among 4578 men who have sex with men (MSM) in Chengdu, China: a retrospective cohort study. Bmc Public Health, 2021. 21(1). 
35. She, M., et al., Associated factors for HIV and syphilis infection among men who have sex with men only and men who have sex with both men and women in cities of China. International Journal of Std \& Aids, 2013. 24(4): p. 293-300.

36. Statistics, P.B.o. Statistical bulletin of national economic and social development of Pengzhou City in 2019. 2020; Available from: http://gk.chengdu.gov.cn/govlnfo/detail.action?id=2638360\&tn=2.

37. Yang, Y., et al., Lifetime commercial heterosexual behavior among HIV negative elderly men from rural Chengdu, China: a modified knowledgeattitude-practice perspective. BMC Public Health, 2021(21): p. 2095.

38. Patel, P., et al., Estimating per-act HIV transmission risk: a systematic review. Aids, 2014. 28(10): p. $1509-1519$.

39. Feng, Y.J., Z.Y. Wu, and R. Detels, Evolution of Men Who Have Sex With Men Community and Experienced Stigma Among Men Who Have Sex With Men in Chengdu, China. Jaids-Journal of Acquired Immune Deficiency Syndromes, 2010. 53: p. S98-S103.

\section{Figures}




\section{ROC Curve}

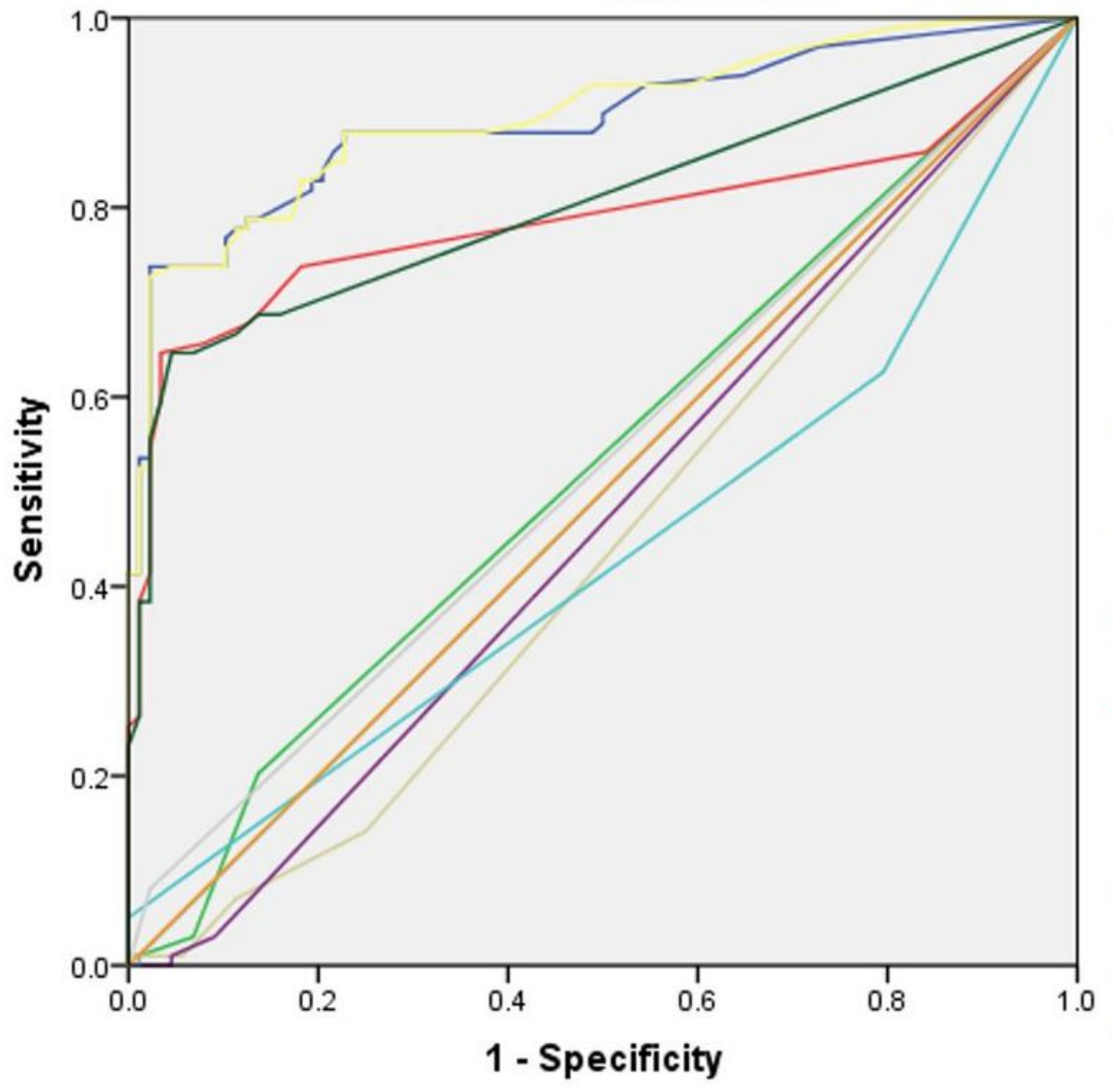

Source of the Curve

Accumulated No. of sexual partners (with both genders)

Accumulated No. of fixed sexual partners (with both genders)

Accumulated No. of extramarital sexual partners (with both genders)

Accumulated No. of casual sexual partners (with both genders)

Accumulated No. of commercial sexual partners (with both genders)

No. of sexual partners within last three years (with both genders) No. of fixed sexual partners within last three years(with both genders) No. of extramarital sexual partners within last three years (with both genders) No. of casual sexual partners within last three years (with both genders) No. of commercial sexual partners within last three years(with both genders)

- Reference Line

Diagonal segments are produced by ties.

\section{Figure 1}

ROC curve and AUCs for number of sexual partners 